\title{
Using absorption and reduced scattering coefficients for non-destructive analyses of fruit flesh firmness and soluble solids content in pear (Pyrus communis 'Conference')- An update when using diffusion theory
}

\begin{abstract}
Quality attributes of fruit determine its acceptability by the retailer and consumer. The objective of this work was to investigate the potential of absorption ( $\mu$ a) and reduced scattering ( $\mu \mathrm{s}^{\prime}$ ) coefficients of European pear to analyze its fruit flesh firmness and soluble solids content (SSC). The absolute reference values, $\mu \mathrm{a}^{*}(\mathrm{~cm}-1)$ and $\mu \mathrm{s}{ }^{*}(\mathrm{~cm}-1)$, of pear were invasively measured, employing multi-spectral photon density wave (PDW) spectroscopy at preselected wavelengths of 515, 690, and $940 \mathrm{~nm}$ considering two batches of unripe and overripe fruit. On eight measuring dates during fruit development, $\mu \mathrm{a}$ and $\mu \mathrm{s}$ ' were analyzed non-destructively by means of laser light backscattering imaging (LLBI) at similar wavelengths of 532, 660, and $830 \mathrm{~nm}$ by means of fitting according to Farrell's diffusion theory, using fix reference values of either $\mu \mathrm{a}^{*}$ or $\mu \mathrm{s}{ }^{*}$. Both, the $\mu \mathrm{a}^{*}$ and the $\mu \mathrm{a}$ as well as $\mu \mathrm{s}$ '* and $\mu \mathrm{s}$ ' showed similar trends. Considering the non-destructively measured data during fruit development, $\mu$ a at $660 \mathrm{~nm}$ decreased 91 till 141 days after full bloom (dafb) from $1.49 \mathrm{~cm}-1$ to $0.74 \mathrm{~cm}-1$ due to chlorophyll degradation. At $830 \mathrm{~nm}$, $\mu$ a only slightly decreased from $0.41 \mathrm{~cm}^{-1}$ to $0.35 \mathrm{~cm}-1$. The $\mu \mathrm{s}$ ' at all wavelengths revealed a decreasing trend as the fruit developed. The difference measured at $532 \mathrm{~nm}$ was most pronounced decreasing from $24 \mathrm{~cm}-1$ to $10 \mathrm{~cm}-1$, while at $660 \mathrm{~nm}$ and $830 \mathrm{~nm}$ values decreased from 15 $\mathrm{cm}-1$ to $13 \mathrm{~cm}^{-1}$ and from $10 \mathrm{~cm}^{-1}$ to $8 \mathrm{~cm}-1$, respectively. When building calibration models with partial least-squares regression analysis on the optical properties for nondestructive analysis of the fruit SSC, $\mu$ a at $532 \mathrm{~nm}$ and $830 \mathrm{~nm}$ resulted in a correlation coefficient of $\mathrm{R}=0.66$, however, showing high measuring uncertainty. The combination of all three wavelengths gave an enhanced, encouraging $R=0.89$ for firmness analysis using $\mu \mathrm{s}$ ' in the freshly picked fruit.
\end{abstract}

Keyword: Absorption; Non-destructive; Pear; Quality; Scattering 